Federal Reserve Bank of Minneapolis

Research Department

\title{
Coexistence of Money and Interest-Bearing Securities
}

\author{
S. R. Aiyagari, Neil Wallace, \\ and Randall Wright*
}

Working Paper 550

Revised April 1996

\begin{abstract}
A random matching model with money is used to study the nominal yield on small denomination, bearer, safe, discount securities issued by the government. There is always one steady state with matured securities circulating at par and, for some parameters, another with them circulating at a discount. In the former, a necessary and sufficient condition for a positive nominal yield on not-yet-matured securities is exogenous discriminatory treatment of them by the government. In the latter, the post-maturity discount on securities induces a deeper pre-maturity discount even without such discriminatory treatment.
\end{abstract}

\footnotetext{
*Aiyagari, Federal Reserve Bank of Minneapolis; Wallace, Federal Reserve Bank of Minneapolis and University of Miami; Wright, Federal Reserve Bank of Minneapolis and University of Pennsylvania. Communication can be addressed to S. R. Aiyagari, Research Department, Federal Reserve Bank of Minneapolis, 250 Marquette Avenue, Minneapolis, MN 55480. FAX (612)-340-2366, e-mail: sra@res.mpls.frb.fed.us. An earlier version of this paper was presented at the Lucas Expectation Anniversary Conference, May 19-20, 1995, Federal Reserve Bank of Minneapolis; and at seminars at the Federal Reserve Bank of Atlanta, the Federal Reserve Bank of Cleveland, the Federal Reserve Bank of Richmond, Johns Hopkins University, the University of Maryland, the University of Pennsylvania, and Washington University. We are indebted to participants for helpful comments. The views expressed herein are those of the authors and not necessarily those of the Federal Reserve Bank of Minneapolis or the Federal Reserve System.
} 
We use a random matching model of fiat currency, one closely related to Shi (1995) and Trejos and Wright (1995), to study the determination of nominal interest rates on securities that have characteristics that potentially make them close substitutes for currency; they are conveniently denominated (small), payable-to-the-bearer (bearer), default-free (safe), and pure discount (discount) securities. There are at least two reasons for studying such securities. First, there are instances in which securities with those characteristics were issued and in which the securities did not function as perfect substitutes for currency, and there is no satisfactory theory that explains why they failed to be perfect substitutes for currency. ${ }^{1}$ Second, and potentially much more important, it would seem that riskless intermediation could convert securities like currently issued U.S. Treasury Bills and other nominally default-free securities into such securities. ${ }^{2}$ Hence, absent a legal prohibition against such intermediation, it would seem that nothing but the costs of such intermediation would limit the spread between the yield on the underlying securities and that on the small, bearer, discount securities-- securities which would be safe by virtue of being backed by the underlying securities. Because the costs would seem to be small, on the order of charges levied by money-market mutual funds, if such intermediation was allowed, then it would seem that interest rates on the underlying securities would be approximately equal to those on the small, bearer, discount securities. However, so far as we know, no one has been able to embed such intermediation into anything like a random matching model of

1 One notable instance was the issue of so-called "bons" by the French government during 1915-1927 (see Makinen and Woodward 1986). In addition to being a fairly lengthy episode, a large amount of "bons" were issued: the amount outstanding in some years exceeded the amount of Bank of France Notes outstanding. Less clear cut instances are discussed in Wallace (1987) and Gherity (1993). Although it seems clear that the securities in these instances did not always trade at par, systematic evidence about the magnitude of the discount on them is not available.

2 We do not know whether the issue of bearer securities in small denominations is legal in the U.S. and other countries. In the U.S., the legal battles that municipalities have encountered when trying to issue such securities suggests that it may not be-- at least de facto. 
currency. That is why we make the existence of small, bearer, safe, discount securities exogenous. ${ }^{3}$

We use a random matching model because we want to, as it were, lean over backward to get such securities to bear interest, to trade at a discount prior to maturity. Using such a model is bending over backward because it gives considerable scope to the familiar notion that the use of a particular object as a medium of exchange is a coordinating device and cannot be explained in terms of the intrinsic properties of the object, including its rate of return (see, e.g., Tobin 1980, p.87). Indeed, versions of such models are known to be consistent with the use as a medium of exchange of objects whose intrinsic properties are worse than those of some other objects (see Kiyotaki and Wright 1989, Aiyagari and Wallace 1992, and Renero 1994, 1995). However, despite having bent over backward in this sense, a main message of our paper is that it is not easy to get small, bearer, safe, discount securities to bear nominal interest. Moreover, when we do succeed in getting them to bear interest, the implied real interest rate depends on all the details of the model, details like the difficulty of redeeming matured securities, and, under plausible specifications of the details, is likely to be low.

The particular random matching model we use has the following features: a continuum of agents who mect pairwise and at random; specialization in the consumption and production of perishable goods which gives rise to a double-coincidence problem in pairwise mcetings; private information regarding individual trading histories which, together with the other assumptions, prevents the double-coincidence problem from being overcome with private credit; and, for tractability, asset indivisibility and an upper bound of unity on individual asset holdings. The specification of the double-coincidence problem is similar to that in Kiyotaki and Wright (1989). Here, in order to allow endogenous determination of the exchange rates among goods, money, and securities, we use a simple version of the bilateral bargaining approach used in Shi (1995) and Trejos and Wright (1995)-- models with a single asset, fiat money. In this paper, we introduce securities into a version of those models in the following way. As in Aiyagari and Wallace (1995), we include a class

${ }^{3}$ Random matching models of currency with private credit include Diamond (1990), Hendry (1992) and Shi (forthcoming). Their specifications preclude circulation of private credit instruments and hint at the difficulty of embedding credit and intermediation into such models in a plausible way. 
of agents, called government agents, who are like private agents and who are subject to the same trading frictions as private agents, but whose behavior is exogenous. Their role is to issue and redeem securitics. Also, we specify exogenously, as part of government policy, what they do when faced with offers of not-yet-matured securties.

The resulting model provides two explanations for the coexistence of money and interestbearing securities in the sense that it has two types of steady states in which such cocxistence can occur. In the first type, which exists for all parameter values, matured securities trade at par. In such a steady state, a necessary and sufficient condition for notyet-matured securities to trade at a discount at some time is that government agents discriminate against them relative to how private agents treat them. Here the discrimination takes the form of an exogenous positive probability that government agents refuse to accept them. (An alternative, with similar consequences, is that government agents accept them but only at an exogenous and positive discount) In the second type of steady state, which exists at least for some parameter values, securities trade at a discount among private agents even after maturity. In such steady states, the post-maturity discount induces a deeper prematurity discount, even if government agents do not discriminate against not-yet-matured securities.

These results imply that a necessary condition for coexistence of money and securities that trade at a discount prior to maturity is that either the government discriminates against notyet-matured securities or matured securities also trade at a discount. As we explain in detail below, we think that this implication is robust in the sense of not being dependent on the details of the model. Moreover, this implication provides predictions, which seem to be new, about what should be observed when, as in the instances cited above, governments issued securities like those in our model: either the government discriminated against notyet-matured securities or matured securities traded at a discount.

Both of our explanations of coexistence imply that the magnitude of the discount on securities depends on all of the details in the model. Our model has preferences and technologies that imply that a version without any frictions has a competitive real rate of interest equal to the common rate of time preference. However, time preference is not the solc determinant of the real interest rate on securities in the model with frictions. In the steady state in which matured securities trade at par, the real interest rate is always less than the rate of time preference and depends on the degrce of discrimination against not-yetmatured securities. In the steady state in which matured securities trade at a discount, the 
real interest rate depends on the frequency of meetings with government agents, the only mectings in which redemption can occur. In addition, in both steady states, the interest rate depends on other parameters, and is sensitive, we suspect, to deviations from the assumptions we make regarding asset indivisibility, the upper bound on individual holdings, and the purely random nature of meetings.

The rest of the paper is organized as follows. In section 1, we describe the model. In section 2 , we study a simple variant of the model with two distinct fiat monies and no securities. This variant provides the ingredients for the results in the more complicated setting with money and securities, because matured securities can be regarded, for most purposes, as a distinct fiat money. In particular, the difference between our two explanations, which rests on whether or not fiat money and matured securities are treated identically, is analogous to whether or not the two fiat monies are treated identically. In section 3 , we present the two steady states which constitute our two explanations for coexistence in the model with money and securities. In section 4 , we discuss the effects of relaxing the assumptions that assets are indivisible and that there is an upper bound on individual asset holdings. We conclude in section 5 .

\section{The Model}

We begin with the underlying environment. We then introduce the assets and government agents. Then we describe how agents bargain in pairwise meetings.

\section{I. The environment.}

Time is discrete and the horizon is infinite. There are $\mathrm{N}$ distinct divisible and perishable goods at each date and there is a $[0,1]$ continuum of each of $N$ types of agents. Each type is specialized in consumption and production in the following way: a type $i$ agent consumes good $i$ and produces good $i+1$ (modulo $N$ ), for $i=1,2, \ldots, N$, where $N \geq 3$. Notice that this rules out a double coincidence of wants in any meeting between two agents. Each type $i$ agent maximizes expected discounted utility with discount factor $\beta \in$ $(0,1)$. Utility in a period is given by $u(x)-y$, where $x$ is the amount of good consumed 
and $y$ is the amount of good produced. 4 The function $u$ is defined on $[0, \infty)$, is increasing and twice differentiable, and satisfies $u(0)=0, u^{\prime \prime}<0$, and $u^{\prime}(0)=\infty$.

Agents meet pairwise at random and each agent's trading history is private information to the agent. Together, these assumptions rule out all but quid pro quo trade for optimizing agents. In particular, they rule out private credit. The only storable objects are indivisible assets (since consumption goods are perishable). Each agent has a storage capacity of one unit of some asset. The role of asset indivisibility and the unit upper bound on individual asset holdings, assumptions which we make in the interest of tractability, is discussed in detail below.

Notice that types are identical except as regards what they consume and produce; that is, $\beta$ and $u$, the measure of each type, the matching process, and asset storage capacity are identical for all types. We have assumed such symmetry so that it makes sense to look for equilibria that are symmetric across types. In fact, those are the only kind of equilibria we consider in this paper.

\subsection{Fiat money, securities, and government agents.}

There are two types of assets in our model: fiat money and finite maturity claims to fiat money in the future, the securities. In order for there to be such securities in a steady state, they have to be created and retired. To accomplish that we use a version of a device used by Aiyagari and Wallace (1995). For each agent type, we let the subinterval $[0, G]$, with $G$ $\in(0,1)$, consist of a class of agents called government agents. The government agents of type $i$ are like the other type $i$ agents, called private agents, in that they are specialized in consumption of good $i$ and production of good $i+1$ and are subject to the same meeting process. Despite this, we exogenously impose the behavior of government agents, which, therefore, is not motivated by their preferences or those of private agents. Among other things, this exogenous behavior permits securities to be issued and redeemed, while the random matching feature of the model is retained.

\footnotetext{
4The assumption that the disutility of production is equal to the amount produced is without Ioss of generality. If we start with a different disutility, say, $d(y)$ with d strictly increasing and convex, and a utility of consumption given by $u^{*}(x)$, then our specification results from letting $\mathrm{z}=\mathrm{d}(\mathrm{y}), \mathrm{u}(\mathrm{z})=\mathrm{u}^{*}\left[\mathrm{~d}^{-1}(\mathrm{z})\right]$ and having agents bargain over the disutility to the producer.
} 
In all but two respects, a type i government agent emulates exactly the actions of type i agents as described below. These two respects involve the issue and redemption of securities, and trades involving not-yet-matured securities. First, government agents sometimes "issue" securities and always stand ready to "redeem" matured securitics. At any date $t$, if a type $i+1$ government agent with a unit of money meets a type i private agent, then with probability $q$ (for quantity of securities) the government agent offers a two-period pure discount bond, rather than the money held and, in effect, destroys the money held. This could be accomplished by having the government agent write on the money held "this matures at $t+2$ ", thereby converting it into a security. At maturity-- that is, at $t+2$ and thereafter-- a private agent holding this security who meets a government agent, can, if he or she wishes, exchange it for a unit of money. In effect, any government agent is willing to erase what was written on the money, thereby turning it back into a unit of money. This rule about how securities are issued and redeemed implies an unchanging total amount of assets, which, per type, is positive and less than one. Second, government agents sometimes reject of fers of securities that have not matured. At any date $t$, government agents reject such offers with probability $r$ (for reject). That is, with probability $r$, they simply refuse to trade when of fered a security that has not matured.

We assume that government agents issue securities which mature in two periods, because two periods is the shortest maturity that permits a discussion of the interesting possibilities and because longer-term securities complicate the presentation without affecting the conclusions. In particular, the conditions which produce a discount on newly issued twoperiod securities would produce a discount on longer-term securities whenever they have at least two periods until maturity, and the conditions under which newly issued two-period securities trade at par imply par values at all dates for longer-term securities. The rejection probability, $r$, is the crucial policy parameter that produces a discount on securities in the steady state in which matured securities trade at par. Instead of a rejection probability, it could have been assumed that government agents exogenously produce less when offered a not-yet-matured security than when offered a unit of money. This too would imply a discount on newly issued securities.

\subsection{The sequence of actions in a period and bargaining.}

The sequence of actions within a period occurs as follows. Each agent, including a government agent, begins a period holding either one unit of an asset or nothing. Then 
agents meet pairwise at random. Agents in pairwise meetings bargain. If the outcome of bargaining implies exchange, then production and consumption occurs. Then agents begin the next period.

In a symmetric equilibrium, any trade among private agents must involve production. That is, it never pays to simply exchange one asset for another. Trade involving production can occur only when a type $i$ agent meets a type $i+1$ agent. In such a meeting, the type $i$ agent, the potential producer, can produce what the type $i+1$ agent, the potential consumer, consumes but, since there are more than two types, the latter cannot supply what the former consumes. Hence, we call this a single-coincidence meeting. Given the upper bound of unity on asset holdings, there are two potential trading situations in single-coincidence meetings: when the consumer has an asset and the producer does not, and when the consumer has a more valuable asset than the producer has. In the former situation, the asset may be traded for some amount of production. In the latter situation, the more valuable asset may be traded for some production and the less valuable asset.

We assume throughout the paper the following very simple bargaining rule: in a singlecoincidence meeting, the consumer makes a take-it-or-leave-it offer and the producer accepts if made no worse off by accepting. A consequence is that the producer does not benefit from the exchange.

Except for the redemption of matured securities, which occurs at the behest of the holder of the matured security in a meeting with any government agent, all trades between government agents and private agents also involve production. Each government agent either starts a period with a unit of money or nothing. (A consequence of our rules about security issue and redemption imply that a government agent never begins a period with a one-period security or with a matured security.) When a government agent with no asset meets a potential consumer with an asset, we assume that the government agent reponds to offers of assets in the same way as does a private agent of the same type, except that with probability $r$ the government agent rejects an offer of a one-period security. When a government agent is a potential consumer, it makes the same take-it-or-leave-it offer that would have been made by a private agent with two exceptions: first, with probability q it offers a two-period security instead of the money and gets as much production for it as possible; and secon, if the private agent has a one-period security, then with probability I the government agent refuses to trade. 
Before we define and present results for symmetric steady states for the above model, we discuss a simpler model with two frat monies, instead of money and securities. This discussion serves two purposes. It provides the main ingredients for the results for the money-securities model and, because it is simpler, provides an introduction to the workings of the money-securities model.

\section{Symmetric steady states with two fiat monies}

As noted in the introduction, we study two monies because of the similarity between a matured security and a distinct kind of money. We begin by assuming that there are no government agents and that there are given outstanding stocks of two kinds of money, money $\mathrm{A}$ and money $\mathrm{B}$. These are distinguished by nothing but some identifiable and irrelevant characteristic like color. We let $\mathrm{pA}>0$ be the per-type amount of money $\mathrm{A}$ and $\mathrm{pB}>0$ the per-type amount of money $\mathrm{B}$, where $\mathrm{pA}_{\mathrm{A}}+\mathrm{p}_{\mathrm{B}}<1$. We make all the assumptions made above. In particular, the monies are indivisible, each agent can hold at most one unit of one money, and bargaining is assumed to take the form of take-it-or-leave-it offers by potential consumers.

Since the labelling of monies is arbitrary, in this section we adopt a notation which presumes that money $\mathrm{B}$ is at least as valuable as money $\mathrm{A}$. We let $c_{\mathrm{j}}$ be the maximum amount produced by someone who has no money in exchange for a unit of money $j$ and we let $\mathrm{c}_{\mathrm{BA}}$ be the maximum amount produced by a holder of money $\mathrm{A}$ who is offered a unit of money $B$. We also let $V_{j}$ be the discounted utility from beginning a period with a unit of money $\mathrm{j}$. A consequence of the bargaining rule we use is that the discounted utility from beginning a period with no money, or, more generally, with no asset, is zero. A person with no asset must be indifferent between accepting a trade and not accepting a trade; not accepting implies a a zero current period reutm (since $\mathrm{u}(0)=0$ ) and beginning the next period with no asset. To conserve on notation, we simply embed that zero value in all our definitions. We also let $\alpha \equiv(1-\mathrm{pA}-\mathrm{pB}) / \mathrm{N}$, the probability of meeting an agent of a particular type holding no money. Using this notation, we have the following definition of a symmetric steady state (in this case also a constant equilibrium).

Defintion 1. A symmetric steady state in which money $B$ is at least as valuable as money $A$ is $\left(\mathrm{C}_{\mathrm{A}}, \mathrm{CB}_{\mathrm{B}}, \mathrm{C}_{\mathrm{BA}}\right)$ and $\left(\mathrm{V}_{\mathrm{A}}, \mathrm{V}_{\mathrm{B}}\right)$ such that

$$
V_{A}=\alpha \max \left[u\left(c_{A}\right), \beta V_{A}\right]+(1-\alpha) \beta V_{A}
$$




$$
\begin{aligned}
& \mathrm{V}_{B}=\alpha \max \left[u\left(c_{B}\right), \beta V_{B}\right]+\left(p_{A} / N\right) \max \left[u\left(c_{B A}\right)+\beta V_{A}, \beta V_{B}\right]+\left(1-\alpha-p_{A} / N\right) \beta V_{B} \\
& c_{j}=\beta V_{j}, j=A, B \\
& c_{B A}=\beta\left(V_{B}-V_{A}\right)
\end{aligned}
$$

In this definition, equation (1) includes the implication of the bargaining rule that producers do not gain in a trade and the convention that money $\mathrm{B}$ is at least as valuable as money $\mathrm{A}$. In equation (1), $\alpha$ is the probability of meeting a potential producer with no money. Such a meeting gives the holder of money $A$ the option between, on the one hand, a current period utility $u\left(c_{A}\right)$ and beginning next period with no money (which, as noted above, has discounted expected utility zero) and, on the other hand, choosing not to trade. With the remaining probability, a holder of money A gets the payoff from not trading. Although a holder of money A may also trade if he or she meets a holder of money $B$ who consumes what the holder of money $A$ produces, such a trade leaves the holder of money $A$ with the same payoff as not trading. Equation (2) describes the probabilities and respective options for a holder of money $B$. The second term represents the options for a holder of money $B$ who meets a potential producer who holds money A. Equations (3) and (4) are implications of take-it-or-leave-it offers by consumers; each expresses the condition that the disutility of producing is equal to the gain in discounted expected utility from changing asset positions.

2.1. Two steady states in which both monies are valuable.

Not surprisingly, there is a steady in which the two monies are not distinguished. In fact, there is exactly one steady state in which the two monies are not distinguished and are valuable.

Lemma 1. There is exactly one symmetric steady state with $\mathrm{c}_{A}=\mathrm{c}_{B}>0$, and $\mathrm{V}_{A}=\mathrm{V}_{\mathrm{B}}>0$. We denote this positive solution for the $c_{j}$ and $V_{j}$ by $c^{*}$ and $V^{*}$, respectively.

The formal versions of all proofs appear in the Appendix, while the text contains outlines of the arguments. If the two assets are cqually valuable, then equation (4) holds by construction and the remaining 4 equations split into two identical pairs. It is immediate-- 
say, from (1) and (3) for $\mathrm{j}=\mathrm{A}-\mathrm{-}$ that there is a unique positive solution and that at that positive solution the maximum in equation (1) is $u\left(c^{*}\right)$.

In addition, there is always a steady state in which both monies are valuable and money $B$ is more valuable.

Lemma 2. There exists a steady state in which $V_{B}>V_{A}>0$. In any such steady state $V_{A}$ $=\mathrm{V}^{*}$.

In lemma $2, V_{A}$ is equal to $V^{*}$, the lemma 1 solution, because only $c_{A}$ and $V_{A}$ appear in equation ( 1 ) and the $j=A$ version of (3). Using $V_{A}=V^{*}$ and substitution from the $j=B$ version of (3), and (4), equation 2 can be written as one equation in $C_{B A}$. Existence can be proved by applying the intermediate value theorem to that equation.

In a lemma 2 steady state, the less valuable money, money $A$, necessarily trades for production. It is also the case that money $\mathrm{B}$ exchanges for money $\mathrm{A}$ plus some production, because otherwise money $B$ would function just like money $A$, and, by lemma 1 , would have to have the same value. It follows that there are only two possible trading patterns, which differ according to whether money $B$ is traded in a single-coincidence meeting when the potential producer has no asset. For some parameters, money $B$ is not traded in this circumstance, while for others it is. For some parameters both kinds of steady states exist. ${ }^{5}$

Notice that a lemma 2 steady state is Pareto superior to a lemma 1 steady state. Those holding nothing or money $A$ are equally well off in the two steady states, while those holding money $B$ are better off in a lemma 2 steady state. An analogue of this result will carry over to the money-securities model.

Since the two monies are flat objects, we should not be surprised that there are steady states with different relative values between them. As we comment on further in section 4 , the

5Shi (1995) and Trejos and Wright (1995) also display steady states in which two frat monies have different values. However, such steady states are due to the existence in their models of multiple steady states with a single valued money. Ours are due to the possibility of trading the more valuable money for the less valuable money, which is not considered in their models. 
kind of multiplicity we find depends on the indivisibility and the upper bound on individual holdings. Given our assumptions, multiple monies permit there to be an endogenous "denominational" difference between the currencies. Given our bargaining rule, the outcome is unambiguously welfare enhancing relative to what can be attained with a single money.

\subsection{Steady states consistent with government transactions.}

Although we will not present a formal analysis of government agents and their trades in the version with two monies, it is instructive to describe government trades that are analogous to those in the money-securities model and their consequences for steady states. The analogue of the issue of new securities is having a government agent, with probability $\mathrm{q}$, offer a unit of money $A$ instead of a unit of money $B$. The analogue of redeeming matured securities is standing ready to tum a unit of money $A$ into a unit of money $B$.

For any $G>0$, the only steady state consistent with both monies being held by private agents and having different positive values is one in which money $B$ is traded in a meeting when the producer has no asset. If money $B$ were not offered in such meetings, then government agents would never acquire money $B$ (if a government agent starts with money $A$ and acquires money $B$ for it and some production, then it is obligated at the same meeting to exchange money $B$ for money $A$ ). Thus, the only steady state consistent with such government trading rules is one in which private agents hold only money $\mathrm{B}$. In the moneysecurities model, this would correspond to a steady state in which no securities are outstanding, which is not of interest to us.

Since we will be appealing, by way of a limiting argument in which $G$ approaches 0 , to existence of a steady state in which money $B$ is more valuable than money $A$ and money $B$ is traded in a meeting when the producer has no asset, we want a sufficient condition on parameters to assure that such a steady state exists. The following lemma, an easy consequence of lemma 2 , provides such a sufficient condition.

Lemma 3. If $(1-\beta) / \beta \geq p_{A} / N$, then there exists exactly one symmetric steady state in which money $B$ is more valuable than money $A$ and trade occurs in every single-coincidence mecting in which the consumer has a more valuable money than the producer or the consumer has either money and the producer has neither. 
The hypothesis of lemma 3 is that the discount factor is not too close to unity. It is not surprising that sufficient impatience gives rise to a steady state in which the chance to trade the more valuable money for production is not passed up. (It can also be shown that for discount factors sufficiently close to one, any lemma 2 steady state is such that money $B$ is not traded in single-coincidence meetings when the producer has no money.)

3. Steady states in the money-securities model

We begin by defining a symmetric steady state. We begin with our notation, which presumes that (i) all matured securities, independent of vintage, are treated identically, (ii) there is symmetry over types of agents, (iii) a unit of money is at least as valuable as a security, and (iv) in a private trade a one-period security exchanges for as much as a matured security. Condition (iv) must hold because a one-period security becomes a matured security before it can be retraded.

At the start of a period, each private agent is holding a security with one-period until maturity, a matured security, a unit of money, or nothing. Therefore, the state of the system at the start of a period can be described by 4 fractions. We let $p_{j}$ be the fraction of each type who are private agents and hold a unit of asset $j$, where $j=1$ means a one-period security, $j=0$ means a matured security, and $j=m$ means a unit of money. We also let $\mathrm{p}_{\mathrm{gm}}$ be the fraction of each type who are government agents and who hold a unit of money. Since we assume that government agents never offer a matured security, $\mathrm{Pgm}$ is also the fraction of each type who are government agents and who hold an asset. We continue to let $\alpha$ denote the probability of meeting a particular type with no asset; that is $\alpha=\left[1-\left(\mathrm{p}_{1}+\mathrm{p}_{0}+\right.\right.$ $\left.\mathrm{p}_{\mathrm{m}}+\mathrm{pgm}_{\mathrm{gm}}\right) \mathrm{I} / \mathrm{N}$. As noted above, the total amount of assets per type is a parameter between 0 and 1. Since this total, in terms of $\alpha$, is $1-N \alpha$, it follows that $\alpha$ is a parameter determined by total assets per type and that $0<\alpha<1 / \mathrm{N}$.

We distinguish 4 produced quantities. There are 3 possibilities for trades of an asset in mectings in which the producer has no asset: $c_{1 n}$ is the amount produced when the producer is offered money, $c_{0}$ is the amount produced when the producer is offered either a matured security or a one-period security, and $c_{2}$ is the amount produced when the producer is offered a 2-period security. Also, $c_{n o}$ is the amount produced in exchange for a unit of money when the producer starts with and gives up a matured security or a one-period security. We also let $V_{m}, V_{0}$, and $V_{1}$ be the discounted expected utility of starting a period with a unit of money, a matured security, and a one-period security, respectively. 
We first describe the conditions that assure that the asset distribution is constant. These conditions are

$$
\begin{aligned}
& p_{1}+p_{0}+p_{m}+p_{g m}=1-N \alpha \\
& p_{1}=\left(1-G-p_{1}-p_{0}-p_{m}\right)\left(p_{g m} / N\right) q \\
& p_{g m}\left[\left(1-\delta_{m}\right) q+\delta_{m}\right]\left(1-G-p_{1}-p_{0}-p_{m}\right) / N= \\
& \quad\left(G-p_{g m}\right)\left[\delta_{0}(1-r) p_{1}+\delta_{m}\left(p_{0}+p_{m}\right)\right] / N \\
& p_{0} G=p_{1}\left\{1-(1-r)\left[\delta_{0}\left(G-p_{g m}\right)+\delta_{m 0} p_{g m}\right] / N\right\}
\end{aligned}
$$

where $\delta_{m}=1$ if $u\left(c_{m}\right)>\beta V_{m}$ (i.e., if money is traded in a single-coincidence meeting when the producer has no asset) and 0 otherwise; $\delta_{0}=1$ if $u\left(c_{0}\right)>\beta V_{0}$ (i.e., if a matured security is traded in a single-coincidence meeting when the producer has no asset) and $O$ otherwise; and $\delta_{m 0}=1$ if $u\left(c_{m 0}\right)+\beta V_{0}>\beta V_{m}$ (i.e., if money is traded in a singlecoincidence meeting when the producer has a matured security) and 0 otherwise.

Equations (5)-(8) are steady state versions of the law of motion. The first two are simple. Equation (5) expresses the constancy of per type holdings of assets in terms of $\alpha$, the probability of meeting a particular type with no asset. Equation $(6)$ equates the outflow and inflow into the fraction of each type who are private agents and who hold a security with one-period until maturity. Since one-period securities mature in the next period, the outflow is equal to the fraction at the last date, $\mathrm{p}_{1}$ in a steady state. The inflow equals the fraction of private agents of that type who were holding nothing at the previous date, 1-G$\mathrm{p}_{1}-\mathrm{p}_{0}-\mathrm{p}_{\mathrm{m}}$, and who met a potential government consumer who offered a security, the probability of such a meeting being $(\mathrm{Pgm} / \mathrm{N}) \mathrm{q}$.

Equation (7) equates the outflow and inflow into the fraction who are government agents of each type holding money. The outflow equals the fraction of such agents in the last period who met and traded with a private potential producer. We are assuming that government agents never offer matured securities; they either offer a two-period security or money. With probability q they offer a two-period security. With probability $1-q$, they either offer a unit of money $\left(\delta_{\mathrm{m}}=1\right)$ or nothing $\left(\delta_{\mathrm{m}}=0\right)$. If $\delta_{\mathrm{m}}=1$, then they al ways give up their 
asset; if $\delta_{m}=0$, then they give it up with probability q. Put differently, with probability 1$q$, they emulate private agents with money. The inflow occurs from meetings in the last period between government agents holding nothing and private agents who are potential consumers and hold an asset. An inflow occurs from private agents holding one-period securities only if two conditions are met: the government agent accepts, which it docs with probability $1-r$, and the offer is made, which occurs if $\delta_{0}=1$; that is, if the private agent would rather consume what can be obtained for a matured security than not trade, matured because the one-period security is equivalent to a matured security to the recipient. If the private agent holds a matured security or money, then there is an inflow if that agent prefers giving up money for $c_{m}$ to entering the next period with money.

Equation (8) equates the outflow and inflow from the fraction of private agents of each type holding matured securties. The outflow is equal to that fraction in the previous period who met a government agent, a meeting which occurs with probability $G$. That is, any meeting between a private agent holding a matured security and a government agent results in a decrease in private holdings of matured securities since, at worst, the government agent turns the matured security into a unit of money. The inflow, the right-hand side, is equal to the per type stock of one-period securities except for those traded to government agents. For a private agent of type $i$, there are two potential sources of trades with government agents: meetings with government agents who are type $\mathrm{i}-1$ and who are not holding an asset and, hence, are potential producers, the probability of which is $\left(\mathrm{G}-\mathrm{p}_{\mathrm{gm}}\right) / \mathrm{N}$; and meetings with government agents who are type $i+1$ and who are holding money and, hence, are potential consumers, the probability of which is $\mathrm{pgm} / \mathrm{N}$. Trades with the former occur if the govemment agent accepts securities prior to maturity and if it is in the interest of the private agent to offer the security, $\delta_{0}=1$. Trades with the latter occur if the government agent accepts not-yet-matured securities and if it is in that agent's interest to make the trade, $\delta_{\mathrm{mo}}=1$.

We now define a steady state. We list the conditions in the definition in an order which facilitates identifying matured securities and money in this version of the model with money $A$ and money $B$ of the two-money version of section 2 , respectively.

Defintion 2. A symmetric steady state in which a unit of money is at least as valuable as a matured security is a list ( $\left.\mathrm{P}_{0}, \mathrm{Pl}_{1}, \mathrm{p}_{\mathrm{m}}, \mathrm{P}_{\mathrm{gm}}, \mathrm{c}_{0}, \mathrm{c}_{2}, \mathrm{c}_{\mathrm{m}}, \mathrm{c}_{\mathrm{m} 0}, \mathrm{~V}_{0}, \mathrm{~V}_{1}, \mathrm{~V}_{\mathrm{m}}\right)$ that satisfies (5)-(8) and:

$$
V_{0}=\left[\left(1-G-p_{1}-p_{0}-p_{11}\right) / N\right] \max \left[u\left(c_{0}\right), \beta V_{0}\right]+
$$




$$
\begin{aligned}
& {\left[\left(G-p_{g m}\right) / N\right] \max \left[u\left(c_{m}\right), \beta V_{m}\right]+\left[G-\left(G-p_{g m}\right) / N\right] \beta V_{m}+} \\
& {\left[1-G-\left(1-G-p_{1}-p_{0}-p_{m}\right) / N\right] \beta V_{0} } \\
V_{m}= & \alpha \max \left[u\left(c_{m}\right), \beta V_{m}\right]+\left[\left(p_{0}+p_{1}\right) / N\right] \max \left[u\left(c_{m n}\right)+\beta V_{0}, \beta V_{m}\right]+ \\
& {\left[1-\alpha-\left(p_{0}+p_{1}\right) / N\right] \beta V_{m} } \\
c_{j}= & \beta V_{j}, j=0, m \\
c_{m 0}= & \beta\left(V_{m}-V_{0}\right) \\
V_{1}= & {\left[\left(1-G-p_{1}-p_{0}-P_{m}\right) / N+(1-I)\left(G-p_{g m}\right) / N\right] \max \left[u\left(c_{0}\right), \beta V_{0}\right]+} \\
c_{2}= & \beta V_{1}
\end{aligned}
$$

Although this definition contains a long list of conditions, they split up into what will be effectively three recursive blocks of equations: (5)-(8), (9)-(12), and (13) and (14). That is, when we look for steady states, we will first solve equations (5)-(8) for the steady state asset distribution for a given trading pattern. Then, given that asset distribution, we will solve (9)- (12), which do not involve $V_{1}$ or $c_{2}$. Then finally, we will solve (13) and (14), which determine what happens in trades involving newly issued securities.

Equations (9)-(12) correspond closely to (1)-(4) provided we identify matured securities with money A and money with money B. That is, (10)-(12) correspond exactly to (2)(4), respectively, provided we use the result, embedded in our definition, that the recipient of a one-period security is indifferent between it and a matured security because the oneperiod security becomes a matured security before it can be retraded. As for (9), it differs from (1) only because government agents treat matured securities as money. In particular, the first term on the right-hand side of (9) is the probability of meeting a potential private producer with no asset times the payoff from such a meeting; the second term is the probability of meeting a potenfial government producer with no asset times the payoff from such a mecting (the government producer can be regarded as first redeeming the matured 
security and then possibly producing for the money); the third term is the probability of meeting any other government agent times the payoff, which is beginning the next period with money; and the last term is the probability of any other meeting times the payoff, which is equal to that of not trading.

Equations (13) and (14) not only form a recursive sub-block, but can be solved one equation at a time. In (13), we again use the fact that a one-period security becomes a matured security next period. The first term is the probability of meeting a potential producer who has no asset and, if a government agent, does not reject securities prior to maturity. With the remaining probability, the payoff is that of no trade. Notice that the right-hand side of (13) is determined by the solution to the other blocks of equations. Equation (14) determines the amount produced when a government agent issues a twoperiod security.

If we compute the yield until maturity in the usual way and with current asset prices taken from the exchanges between assets and goods, then the yield of one-period securities is $\left(c_{1 n} / c_{0}\right)-1$, while the yield of two-period securities is $\left[\left(c_{m} / c_{2}\right)-1\right]^{1 / 2}$. The former is positive if and only if matured securities trade at a discount $\left(c_{0}<c_{m}\right)$; the latter, by (11) and (14), is positive if and only if $V_{1}<V_{m}$. For us, any steady state with a positive yield on two period securities $\left(c_{2}<c_{m}\right)$ is a steady state that displays coexistence of money and interest-bearing securities.

We first describe a steady state in which matured securities and money are treated identically. Then we describe a steady state in which matured securities trade at a discount in private trades.

\subsection{Matured securities exchange at par.}

If money and matured securities are treated identically, then both are traded in singlecoincidence meetings when the producer has no asset; that is, $\delta_{m 1}=\delta_{0}=1$ in equations (5)-(8). Moreover, since with such identical treatment, it is not necessary to distinguish between holdings of matured securities and money, we need only find $\mathrm{p}_{1}, \mathrm{p}_{0}+\mathrm{p}_{\mathrm{m}}$, and Pgm. The following lcmma, which uses the fact that po and $\mathrm{Pm}$ appear in equations (5)-(7) only as a sum, shows that those equations have a unique solution. 
Lemma 4. If $\delta_{\mathrm{m}}=\delta_{0}=1$ in (5)-(7), then there exists a unique solution to $(5)$-(7) with $\left(\mathrm{Pl}, \mathrm{pO}+\mathrm{p}_{\mathrm{m}}, \mathrm{Pgm}\right) \in \mathrm{R}_{++}^{3}$. Moreover, the solution for $\mathrm{pgm}_{\mathrm{gm}}$ is strictly decreasing in $\mathrm{r}$, strictly decreasing in $\mathrm{q}$ if $\mathrm{r}>0$, and satisfies $\mathrm{pgm}_{\mathrm{gm}}<\mathrm{G}$; while the solution for $\mathrm{p}_{1}$ is strictly decreasing in $r$ and $q$.

We prove this lemma by studying the cubic equation in Pgm obtained from (5)-(7) by substitution. With this result in hand, we can turn to the main proposition.

Proposition 1. A necessary and sufficient condition for existence of a steady state in which matured securities exchange at par $\left(c_{0}=c_{m}\right)$ and newly issued securities exchange at a discount $\left(0<c_{2}<c_{0}\right)$ is $r>0$. Moreover, if $r=0$, then there is a steady state in which securities always exchange at par $\left(0<c_{2}=c_{0}=c_{m}\right)$.

The necessity part of this proposition is established by contradiction. In particular, to prove it, we assume $r=0$ and $c_{0}=c_{m}>0$ and show that a consequence is $c_{2}=c_{m}$. The argument is straightforward backward induction: if a security is equivalent to money at $t+1$, then a private potential producer treats it as money at $t$, because $t+1$ is the earliest date at which it will be retraded; and, with $r=0$, government agents, by assumption, produce as much as private agents when offered a one-period security. It follows, then, from (13) that $\mathrm{V}_{1}=\mathrm{V}_{\mathrm{m}}$, which, in turn, implies, via (14), that $c_{2}=c_{\mathrm{m}}$.

The sufficiency part, including existence for $r=0$, involves showing that the conditions in definition 2 are satisfied. Given the asset distribution established in lemma 4 , this is done in two simple steps using the recursive structure of equations (9)-(14). The first step is to show that (9)-(12) have a solution. Under the hypothesized strategies, (9)-(12) become identical to (1)-(4) of the two-money model. Therefore, the solution is $c_{m}=c_{0}=c^{*}$, as in lemma 1. The second step is to read off the solutions for $V_{1}$ and $c_{2}$ from (13) and (14), respectively. In this solution, $r>0$ implies $V_{1}<V_{m}$ and, hence, $c_{2}<c_{m}$, a discount on newly issued securities, because the potential producer who accepts a newly issued security may meet a government agent at the next date who will reject a trade with probability 5 .

The necessity part of proposition 1 says that if matured securities are perfect substitutes for money, then so are not-yet-matured securities unless there is exogenous nonacceptance by some agents. In other words, if matured securities trade at par, then the belief that other 
agents will not accept not-yet-matured securities at par is not an equilibrium belief unless supported by exogenous nonacceptance by some agents.

Some features of the steady state displayed in the sufficiency part of proposition 1 deserve comment. In that steady state, a unit of money exchanges for the $c^{*}$ of lemma 1 . It follows that in a proposition I steady state, the value of a unit of money (the inverse of the price level) depends only on the total amount of assets and not on q or $\mathrm{r}$. 6 The policy parameters $q$ and $r$ do affect the steady-state distribution of asset holdings between government agents and private agents, the composition of private asset holdings between one-period securities, on the one hand, and money and matured securities on the other hand, and, by way of those effects and directly via (13), the discount on newly issued securities. Since, by (13), $V_{1}=\alpha^{\prime} u\left(c^{*}\right)+\left(1-\alpha^{\prime}\right) \beta V^{*}$, where, $\alpha^{\prime}=\alpha-r(G-P g m) / N$, and since the solution for Pom is decreasing in $r$ and $q$, it follows that $V_{1}$ is decreasing in $r$ and q. Therefore, the nominal interest rate on newly issued securities, $\left(c^{*} / c_{2}\right)-1$, is increasing in $r$, the probability of rejection, and, for any $r>0$, is increasing in $q$, the probability of security issue. The dependence of the discount on two-period securities is as expected; the higher is $r$, the more likely that a two-period security will not be accepted in a trade at the next date, and, therefore, the greater the discount required in order that an agent accept it. The yield on two-period securities, regardless of $q$ and $r$, is bounded above by the rate of time preference because $c_{2} / c^{*}=V_{1} / V^{*}>\beta$. (The equality follows from (11) and (14) and the inequality from $V_{1}>\beta V^{*}$, which says that a one-period security can at worst be held until it matures.) However, the rate of time preference is a poor upper bound on the yield, because acceptance of the security does not delay consumption for sure relative to what occurs with money.

3.2. Matured securities exchange at less than par.

Proposition $I$ implies that with $r=0$ any steady-state in which securities trade at a discount has to be one in which matured securities do not exchange at par in trades between private agents. Therefore, we now explore that possibility. We now assume $r=0$ in order to isolate the role of matured securities exchanging at less than par. In a steady state in which matured securities trade at less than par in private transactions, the value of securities when

\footnotetext{
6This feature can be attributed partly to the absence of taxes in the model; if there were taxes in the model, then the value of money could well depend on $q$ and $r$, as well as on the details of the tax system.
} 
issued will be less than their value in private trades after maturity because it is only after maturity that govemment agents redeem securities.

We begin by presenting some necessary conditions for a steady state in which matured securities trade at a discount.

Lemma 5. If in a steady state money has value, matured securities trade at a discount, and private agents hold securities, then trade occurs in every single-coincidence meeting in which the consumer has a more valuable asset than the producer or the consumer has an asset and the producer does not (in particular, $\delta_{m}=\delta_{0}=\delta_{\mathrm{m} 0}=1$ ). Moreover, if $r=0$, then the unique positive solution to (5)-(8) in such a steady state safisfies (i) $\mathrm{Pgm}=\mathrm{G}(1-$ $N \alpha$ ) and (ii) $p_{1}+p_{0}=q \alpha\left(1-N_{\alpha}\right)(1-G)\left[1+G\left(1-N^{-1}\right)\right]$.

The results about the trading pattern are established as follows. First, if $V_{m}>0$ and $V_{0} \leq$. $V_{m}$, then $V_{m} \geq V^{*}$ and $V_{0} \geq V^{*}$, where $V^{*}$ is the lemma 1 solution for valued moncy. That is, if money is valuable, then both money and securities must be at least as valuable as money in the lemma 1 solution for the same total amount of assets. This follows from equations (9) and (10). (In particular, a matured security cannot be worthless because with positive probability it can be converted into money.) From this, we are able to conclude that if $V_{m}>V_{0}$ (money is more valuable than securities), then $\delta_{\mathrm{m} 0}=1$; that is, money is traded when the producer has a matured security. (If not, then the only positive value for money is its positive value in lemma $1, V^{*}$, which contradicts $V_{m}>V_{0} \geq V^{*}$.) Finally, the requirement that the steady state have securities in private hands, $\mathrm{pl}+\mathrm{po}>0$, implies that $\delta_{\mathrm{m}}=\delta_{0}=1$. That is, unless both matured securities and money are traded when the producer has no asset, then there could not be a steady state in which securities are outstanding.

Since $\delta_{m}=\delta_{0}=1$, the solution to (5)-(7) given in lemma 4 applies. With $r=0$, that solution takes a simple form. Conclusion (i) says that the fraction of government agents with an asset is equal to the fraction of private agents with an asset. Conclusion (ii) tells us about the behavior of private holdings of one-period and matured securities. In particular, it implies that $\mathrm{p}_{1}+$ po is continuous and decreasing in $\mathrm{G}$, with limit $\mathrm{q} \alpha(1-\mathrm{N} \alpha)$ as $\mathrm{G} \rightarrow 0$ and limit 0 at $G \rightarrow 1$. The limiting behavior of $\mathrm{pgm}_{\mathrm{gm}}$ and $\mathrm{p}_{1}+\mathrm{p}_{0}$ as $\mathrm{G} \rightarrow 0$ plays a role in proposition 2, which establishes existence of a steady state with matured securities at a discount when $G$ is sufficiently small. Notice that although $p_{I} \rightarrow 0$ as $G \rightarrow 0$, podoes 
not, because on average securities remain outstanding for a number of periods that approaches infinity as $\mathrm{G} \rightarrow 0$.

Proposition 2. Assume $r=0$ (government agents treat one-period securitics as do private agents). If $G$ is sufficiently close to 0 and $(1-\beta) / \beta \geq q \alpha(1-N \alpha) / N$, then there exists a steady state with matured securities exchanging at less than $\operatorname{par}\left(c_{0}<c_{m}\right.$ and $\left.c_{m 0}>0\right)$ and with newly issued securities exchanging at less than matured securities $\left(c_{2}<c_{0}\right)$.

The proof proceeds by verifying that there is a solution to the equations in definition 2 that satisfy the inequalities $V_{m}>V_{0}>0$. It uses the recursive structure of the conditions in definition 2 that we noted above, and, therefore, has three steps. The first step, the solution for the asset distribution, is accomplished in lemma 5. The second step is to show that equations (9)-(12) have a solution with $c_{m}>c_{0}>0$. To do that we rely on the implicit function theorem, lemma 3 , and the correspondance between (9)-(12) and (1)-(4) with $\left(\mathrm{c}_{0}, \mathrm{c}_{\mathrm{m}}, \mathrm{c}_{\mathrm{mo}}, \mathrm{V}_{0}, \mathrm{~V}_{\mathrm{m}}\right)$ corresponding to $\left(\mathrm{c}_{\mathrm{A}}, \mathrm{c}_{\mathrm{B}}, \mathrm{c}_{\mathrm{BA}}, \mathrm{V}_{\mathrm{A}}, \mathrm{V}_{\mathrm{B}}\right)$

Since (11) and (12) correspond exactly to (3) and (4), we have to show that the right-hand sides of (9) and (10) are continuous in $G$ and approach the right-hand sides of (1) and (2), respectively, as $G \rightarrow 0$. Since $\mathrm{Pgm}_{\mathrm{g}}=\mathrm{G}(\mathrm{I}-\mathrm{N \alpha}$ ), the right-hand side of (9) is continuous in $G$ and approaches $\alpha u\left(c_{0}\right)+(1-\alpha) \beta V_{0}$, which is the same as the right-hand side of (1). $G$ appears in (10) implicitly by way of the sum $p_{1}+p_{0}$, which, as noted above, is continuous in $\mathrm{G}$ and approaches $q \alpha(1-\mathrm{N} \alpha)$ as $\mathrm{G} \rightarrow 0$. Thus, the right-hand side of (10) is continuous in $G$ and approaches the right-hand side of (2) as $G \rightarrow 0$, provided we replace $p_{A}$ in (2) by $q \alpha(1-N \alpha)$. In addition, we need two other conditions. First, the solution at $G=0$ is in the interior of the domain, because the solution in lemma 3 satisfies $c_{B}>c_{A}=$ $c^{*}>0$. Second, the non vanishing Jacobian condition is satisfied, because the lemma 3 solution satisfies that condition. It follows, then, from the implicit function theorem applied to (9)-(12) that if $G$ sufficiently close to zero, then equations (9)-(12) have a solution in the neighborhood of the lemma 3 solution. Since the lemma 3 solution satisfies the conditions for the trades to be optimal with strict inequalities, it follows from continuity of the solution to (9)-(12) in $G$ that those strict inequalities also hold for $G$ sufficiently close to zero.

The third step amounts to noting obvious properties of the solutions to (13) and (14). In particular, the conclusion that newly issued securities trade for less than do matured securities $\left(c_{2}<c_{0}\right)$ follows from comparing the expression for $V_{0}$, equation (9), and that 
for $V_{1}$ equation (13). Since $V_{m}>V_{0}$, it follows that $V_{0}>V_{1}$, which, in turn, implies $c_{2}<$ $c 0$, a deeper discount on two-period securities than on matured securities.

In addition to proposition 2 , we have one other result concerning steady states in which matured securities trade at a discount: the discount, if it exists, approaches zero as either $G$ $\rightarrow 1$ or $\mathrm{q} \rightarrow 0$. It follows from lemma 5 that $\mathrm{p}_{1}+\mathrm{p}_{0} \rightarrow 0$ as either $\mathrm{G} \rightarrow 1$ or $\mathrm{q} \rightarrow 0$. But, then by, $(10)$, it follows that $V_{m} \rightarrow V^{*}$. Since we know that $V_{0} \geq V^{*}$, it follows that $V_{0}$ $\rightarrow V_{m}$ which implies that the discount on matured securities, if one exists, approaches zero as either $\mathrm{G} \rightarrow 1$ or $\mathrm{q} \rightarrow 0$.

We are not, of course, making any claim of necessity for the hypotheses of proposition 2. Indecd, as regards $\mathrm{G}$, we have computed examples in which the conclusions of proposition 2 hold for all G's-- although, consistent with the claim just made, the discount on matured securities in these examples gets smaller as $G$ gets larger. This is not surprising because $G$ is the frequency of encountering a government agent who must convert a matured security into money and because the discount on a matured security ought to be smaller the more likely is such conversion. As regards the discount factor, some bound away from unity seems to be necessary to assure that money is traded when the producer has no asset (which, as noted above, is necessary for a steady state with securities outstanding). ${ }^{7}$

There is a sense in which proposition 2 provides a welfare rationale for securities. Although the consumption and production of government agents vary across steady states, which in general implies that we should not ignore what happens to them in different steady states, what happens to them is not important if $\mathrm{G}$ is near zero. Ignoring government agents, the steady state of proposition 2 is Pareto superior to that of proposition 1 . And, since with $r=0$, the proposition 1 steady state is the same as a steady state with one money and no securities, we have the conclusion that there is a steady state with securities outstanding that is Pareto superior to any steady state with only one kind of money outstanding. Moreover, those steady states are comparable in the sense that the asset

${ }^{7}$ Letting $\pi=N \alpha$, the fraction of each type without an asset, the sufficient condition on the discount factor in proposition 2 can be written as $(1-\beta) / \beta \geq q \pi(1-\pi) / N^{2}$ or $\beta \leq 1 /[1+q \pi(1-$ $\left.\pi) / N^{2}\right] \leq 1 /\left[1+1 / 2 N^{2}\right]=2 N^{2} /\left[1+2 N^{2}\right]$. Hence, the stringency of that condition varies inversely with $N^{2}$. Since $N=3$ is the smallest $N$ we permit, $\beta \leq 18 / 19$ is sufficient. 
distribution of the proposition 2 steady state is the steady state asset distribution of proposition 1 .

4. The role of asset indivisibility and the bound on asset holdings

Among the many extreme assumptions made in our model, perhaps the most extreme is the combination of asset indivisibility and the upper bound of unity on holdings of assets. Those assumptions seem to preclude direct choice among assets; for example, no one is ever in the position of choosing between offering a unit of money or a matured security. Here we discuss some suspicions about the consequences of weakening the upper bound on asset holdings and the indivisibility of assets.

It is straightforward to formulate versions of the model with indivisible assets and a general integer upper bound or no upper bound on individual asset holdings or a version with divisiblc assets and no bound on individual holdings (see Trejos and Wright 1995). However, for such versions, we have not been able to describe or establish existence of steady states in which trade occurs. Nevertheless, we have some suspicions about the robustness of propositions 1 and 2 to such generalizations of the model.

As regards proposition 1, we suspect that the necessity part of that proposition will survive such generalizations of the model. That is, we suspect that the following is true: if there is a steady state in which matured securities and moncy are perfect substitutes, then absent exogenous non acceptance or some other discrimination against not-yet-matured securties, they are perfect substitutes prior to maturity. The sufficiency parts are more problematic, because they require existence arguments. The result that $r=0$ implies existence of a steady state in which securities and money are always perfect substitutes is simply the claim that the corresponding one money world has a steady state with valued money. That $r>0$ is sufficient to generate a discount on matured securities could, in a sense, be explored even without a general existence argument by considering the following conjecture: if there is a steady state in which matured securities and money are perfect substitutes and if $r>0$, then newly issued 2-period securities necessarily sell at a discount. However, even such a limited clatm does not seem easy to prove. This result in our version was easy to prove because the upper bound on asset holdings implies that someone with a not-yet-matured security could meet a government agent and have only that asset to offer. With more general portfolios, the conclusion about the discount will follow if portfolios and trades are such that $r>0$ will be binding in some trades with government agents. That, however, 
depends on the portfolios and on the trades, both of which are endogenous. This is one reason why we say that our message is that getting a discount on small, bearer, safe, discount securities is not easy.

More general portfolios could also have consequences for proposition 2. Since proposition 2 rests on the results for two distinct kinds of money, let us consider a two money setting, but with divisible assets and no bound on each agent's holdings. In this case, we know that there is exchange rate indeterminacy in the following sense: if there is an equilibrium in which one money has value for an arbitrary initial distribution of the money, then with two monies there is an equilibrium for any arbitrary relative value between the two monies that is constant through time. Given this indeterminacy, we lose the non vanishing Jacobian condition, which is the basis for the implicit function theorem argument we use to prove proposition 2. That, of course, does not imply non existence of an equilibrium in which matured securities trade at less than par. It does, though, raise suspicions.

We do not mean to suggest by these remarks that the limiting case of asset divisibility is the only case of interest. Most assets are to some extent indivisible. Although asset indivisibility can be ignored when markets are complete because the completeness permits assets to be shared, an appeal to sharing, using intermediation or some other credit device, is not available under the assumptions that imply that trade is quid pro quo in pairwise meetings. Therefore, results for the case of divisibility in such painvise meeting models are of interest primarily as a limiting case of what happens as indivisibilities get less important. Nevertheless, if proposition 2 were to fail when assets are perfectly divisible, then that would presumably tell us that the possible discount on matured securities gets small as assets become less indivisible.

Notice that the necessity part of proposition 1 provides the result noted in the introduction; namely, coexistence of non interest-bearing money and interest on securities like ours implies either exogenous nonacceptance of not-yet-matured securities or a discount on matured securities in private transactions. In accord with the discussion of proposition 1 above, this implication is aimost certainly robust to departures from the indivisibility of assets, the upper bound on individual asset holdings, and to other details of the specification.

\section{Conclusion}


Al though our model is extreme in many respects, it has some virtues relative to standard models of money. The model has explicit frictions that limit transactions and those frictions are not connected to particular assets. The frictions are random pairwise meetings, private information about trading histories, indivisible assets, and a unit storage capacity. They apply to securities and to money. The presence of the frictions and their application to all assets is what generates some new results.

First, the model makes new predictions about episodes in which governments issued securities with features that made them in various degrees suitable as forms of currency. Such securities were issued by the U.S. during the Civil War (see Gherity 1993) and during World War I (see the discussion of Liberty Bonds in Wallace 1987), and in France during the years 1915-27 (see Makinen and Woodward 1986). The French experience is notable because the government made widely available, at prices that implied roughly $5 \%$ yields until maturity, small denomination, pure discount, seemingly default-free, bearer securities with maturities of 3 months, 6 months, and 1 year. In all these instances, the evidence seems to be that such securities did not trade at prices that implied zero nominal yields at all times. Our model makes the following predictions about these and other such episodes. Either there should have been rules dictating that the government treated not-yetmatured securities in some special unfavorable way, such as not accepting them or accepting them only at an exogenously specified discount, or matured securities should have traded at a discount in private transactions. So far as we knowv, these predictions have not been considered in existing discussions of episodes of coexistence between non interest-bearing money and interest-bearing small, bearer, safe securities.

Second, although our explanation that relies on exogenous nonacceptance by government agents is a form of legal restriction, it is a different kind of lcgal restriction than those that have been used in models with complete markets. In models with complete markets (c.g., Sargent and Wallace 1982 or Bryant and Wallace 1984), in order the produce the coexistence, the legal restriclions have to restrict what private agents can do-- in particular, they have to restrict the forms in which people can hold wealth. ${ }^{8}$ Here, because of the pairwise-meeting feature, we get coexistence from a legal restriction that limits only what

8 Makinen and Woodivard (1986) and Gherity (1993) interpret the cvidence that small, bearer securities were not used as perfect substitutes for currency as evidence against the legal restrictions theory as set out by Wallace (1983). It secms as if ncither they nor Wallace considered legal restrictions of the sort used here. 
the government accepts. Such a restriction would not suffice in models with complete markets, because the price of securities adjusts to make the marginal holder, a private agent if both money and securities are outstanding, indifferent between the two.

Third, our model says that if securities have characteristics that make them potentially close substitutes for money (i.e., they are small, bearer, safe, and discount securities), then it is not casy to get them to function as imperfect substitutes for currency. In addition, if one succeeds in getting them to function that way and, hence, to bear interest, then the magnitude of the interest rate will depend on all the details that produce the imperfect substitutability. Moreover, for many ways of producing the imperfect substitutability, the implied real interest rate on the securities will be low, low relative to what we would find in the comparable model without frictions or in the coparable model with money, but not securities, as an argument of utility functions or as the cash in a cash-in-advance constraint.

Those conclusions are about securities that have characteristics that make suitable to serve as currency. Do they have implications for yields on other securities? We are not sure The actual economy resembles in some respects the random matching model we have studied. However, it also contains a great deal of financial intermediation. The theoretical challenge is to include in a model in a plausible way both the frictions that give rise to a role for currency and financial intermediation. Meeting that challenge should go a long way toward helping us decide why interest rates on all securities seem not to be determined by the kinds of details that in our model determine interest rates on small, bearer, safe, discount securities. In particular, it should help us decide whether that is due to natural frictions or is due to legal restrictions that preclude intermediation of securities like book entry Treasury Bills into small, bearer, safe, discount securities. 


\section{References}

Aiyagari, S. R, and N. Wallace, 1992. Filat money in the Kiyotaki-Wright model. Economic Theory, 2, 447-464.

Aiyagari, S. R., and N. Wallace, 1995. Government transaction policy, the medium of exchange, and welfare. Research Department Working Paper 516, Federal Reserve Bank of Minneapolis.

Bryant, J. B., and N. Wallace, 1984. A price discrimination analysis of monetary policy. Review of Economic Studies, 51, 279-288.

Diamond, P., 1990. Pairwise credit in search equilibrium. Quarterly Journal of Economics, 105, 285-319.

Gherity, J.A., 1993. Interest-bearing currency: evidence from the Civil War experience. Journal of Moncy, Credit and Banking , 25, 125-131.

Hendry, S., 1992. Credit in a search model with money as a medium of exchange. University of Western Ontario.

Kiyotaki, N., and R. Wright, 1988. On money as a medium of exchange. Journal of Political Economy, 97, 927-954.

Makinen, G. E., and G. T. Woodward, 1986. Some anecdotal evidence relating to the legal restrictions theory of the demand for money. Joumal of Political Economy, 94, 260265.

Renero, J., 1994. Gresham's Law type cquilibria in the Kiyotaki-Wright model. ITAM Discussion Paper 9411.

Renero, J., 1995. Welfare of alternative equilibrium paths in the Kiyotaki-Wright model", ITAM Discussion Paper 9502.

Sargent, T. I, and N. Wallace, 1982. The real-bills doctrine versus the quantity theory: a reconsideration. Journal of Political Economy, 90, 1212-1236. 
Shi, S., 1995. Money and prices: a model of search and bargaining. Journal of Economic Theory, 67, 467-498.

Shi, S. , forthcoming. Credit and money in a search model with divisible commodities. Review of Economic Studies.

Trejos, A. and R. Wright, 1995. Search, bargaining, money and prices. Journal of Political Economy, 103, 118-141

Tobin, J. 1980. Discussion, in: J.H. Kareken and N. Wallace, eds, Models of monetary cconomies, (Federal Reserve Bank of Minneapolis, Minneapolis)

Wallace, N., 1983. A legal restrictions theory of the demand for 'money' and the role of monetary policy. Federal Reserve Bank of Minneapolis Quarterly Review, 7 Winter, I-7

Wallace, N., 1987. A suggestion for oversimplifying the theory of money. Economic Journal, Supplement, 98, 25-36. 


\section{Appendix}

Lemma 1. There is exactly one symmetric steady state with $c_{A}=c_{B}>0$, and $V_{A}=V_{B}>0$. We denote this positive solution for the $\mathrm{c}_{\mathrm{j}}$ and $\mathrm{V}_{\mathrm{j}}$ by $\mathrm{c}^{*}$ and $\mathrm{V}^{*}$, respectively.

Proof. We solve equations (1)-(4) under the assumption that $c_{j}=c, V_{j}=V$ and $u(c) \geq \beta V$ and then verify that the solutions satisfy this inequality. It follows that $\mathrm{c}_{\mathrm{BA}}=0$ and that (2) reduces to (1). Therefore, we have only to find pairs $(c, V)$ that satisfy $V=\alpha u(c)+(1-$ $\alpha) \beta V$ and $c=\beta V$. Upon eliminating $V$, we get $[\alpha+(1-\beta) / \beta] c=\alpha u(c)$. The assumptions about $u$ imply that there are exactly two solutions: $c=0$, the no-trade solution, and a positive solution, denoted $\mathrm{c}^{*}$, which satisfies $\mathrm{c}^{*}<\mathrm{u}\left(\mathrm{c}^{*}\right)$. The corresponding $\mathrm{V}^{\prime} \mathrm{s}$ can be found from (3). That for $c^{*}$, which we denote $V^{*}$, is positive. Since $c^{*}<u\left(c^{*}\right)$, it follows from (3) that $u\left(c^{*}\right)>\beta V^{*}$.

Lemma 2. There exists a steady state in which $V_{B}>V_{A}>0$. In any such steady state $V_{A_{A}}$ $=\mathrm{V}^{*}$.

Proof. Equation (1) and equation (3) for $j=A$ involve only $c_{A}$ and $V_{A}$. Therefore, as demonstrated in the proof of lemma 1 , they have a unique positive solution, ( $\mathrm{C}^{*}, \mathrm{~V}^{*}$ ), which satisfies $\mathrm{u}\left(\mathrm{c}^{*}\right)>\beta \mathrm{V}^{*}$. On the hypothesis, to be verified later, that money $\mathrm{B}$ is traded for money $\mathrm{A}$, equation (2) can be written as

$$
(1-\beta) V_{B}=\alpha \max \left[u\left(c_{B}\right)-\beta V_{B}, 0\right]+\left(p_{A} / N\right)\left[u\left(c_{B A}\right)-\beta\left(V_{B}-V^{*}\right)\right]
$$

Then, using (3) and (4) to express each of $c_{B}$ and $V_{B}$ in terms of $c_{B A}$ and $V^{*}$, we can rewrite (A1), solely in terms of $c_{B A} \equiv x$, as $F(x)=H(x)$, where

$$
F(x)=[(1-\beta) / \beta]\left(x+\beta V^{*}\right)
$$

and

$$
H(x)=\alpha \max \left[u\left(x+\beta V^{*}\right)-\left(x+\beta V^{*}\right), \text { of }+\left(p_{A} / N\right)[u(x)-x]\right.
$$

Since $F(0)=H(0)$, the lemma 1 solution, and $H^{\prime}(0)=\infty$, it follows that $F(x)<H(x)$ for $x$ $>0$ and $x$ sufficiently close to 0 . Let $x$ " be the unique positive solution for $x$ to $u(x)-x=$ 0 . This exists given the assumptions about $u$ and $H\left(x^{\prime \prime}\right)=0$. Therefore, $F\left(x^{\prime \prime}\right)>H\left(x^{\prime \prime}\right)$, Since $F$ and $H$ are continuous, it follows that there is at least one $x \in(0, x ")$ that satisfies 
$F(x)=G(x)$. Since, by definition of $x^{\prime \prime}, u(x)>x$ for all $x \in\left(0, x^{\prime \prime}\right)$, the trade of money $B$ for money $A$ is, in fact, optimizing.•

Lemma 3. If $(1-\beta) / \beta \geq \mathrm{pA} / \mathrm{N}$, then there exists a unique symmetric steady state in which money $B$ is more valuable than money $A$ and trade occurs in every single-coincidence mecting in which the consumer has a more valuable money than the producer or the consumer has either money and the producer has neither.

Proof. Let $x^{\prime}$ be the unique nonnegative solution to $u\left(x^{\prime}+\beta V^{*}\right)-\left(x^{\prime}+\beta V^{*}\right)=0$. Then $F\left(x^{\prime}\right)-H\left(x^{\prime}\right)=[(1-\beta) / \beta]\left(x^{\prime}+\beta V^{*}\right)-(p A / N)\left[u\left(x^{\prime}\right)-x^{\prime}\right]=[(1-\beta) / \beta] u\left(x^{\prime}+\beta V^{*}\right)-$ $\left(\mathrm{p}_{\mathrm{A}} / \mathrm{N}\right) \mathrm{u}\left(\mathrm{x}^{\prime}\right)+\left(\mathrm{p}_{\mathrm{A}} / \mathrm{N}\right) \mathrm{x}^{7}>0$, where $\mathrm{F}$ and $\mathrm{H}$ are as defined in the proof of lemma 2 and where the incquality follows from the hypothesis. As established in the proof of lemma 2, $\mathrm{F}(\mathrm{x})<\mathrm{H}(\mathrm{x})$ for $\mathrm{x}>0$ and $\mathrm{x}$ sufficiently close to zero. Therefore, there is a unique solution to $F(x)=H(x)$ with $x \in\left(0, x^{\prime}\right)$. By construction, this is a solution where the max term in (A1) is positive. Moreover, since $H$ is strictly concave for $x \in\left(0, x^{\prime}\right)$, there is only onc such solution.•

Lemma 4. If $\delta_{\mathrm{m}}=\delta_{0}=1$, then there exists a unique solution to (5)-(7) with $\left(\mathrm{p}_{\mathrm{t}} \mathrm{p}_{\mathrm{p}}+\mathrm{p}_{\mathrm{m}}, \mathrm{p}_{\mathrm{gm}}\right) \in \mathrm{R}_{++-}^{3}$. Moreover, the solution for $\mathrm{p}_{\mathrm{gm}}$ is strictly decreasing in $\mathrm{r}$, strictly decreasing in $q$ if $r>0$, and satisfies $p_{g m}<G$; while the solution for $p_{1}$ is strictly decreasing in $r$ and $q$.

Proof. Letting $\mathrm{A} \equiv 1-\mathrm{Na}$ and $\mathrm{p} \equiv \mathrm{p}_{0}+\mathrm{p}_{\mathrm{m}}$ and using the hypotheses, (5)-(7) become, respectively,

$$
\mathrm{p}_{1}+\mathrm{p}+\mathrm{p}_{\mathrm{gm}}=\mathrm{A}
$$

$$
\mathrm{p}_{\mathrm{I}}=\left(\mathrm{I}-\mathrm{G}-\mathrm{p}-\mathrm{p}_{1}\right)\left(\mathrm{p}_{\mathrm{gim}} / \mathrm{N}\right) \mathrm{q}
$$

$$
p_{g m}\left(1-G-p-p_{1}\right)=\left(G-p_{g m}\right)\left[(1-r) p_{1}+p\right]
$$

We begin by obtaining a single equation in $\mathrm{Pgm}_{\text {gm }}$ that must be satisfied by any solution to (A2) - (A4). Solving (A2) for $\mathrm{p}_{1}+\mathrm{p}$ and substituting the result into the right-hand side of (A3), we get

(AS) $\quad p_{1}=\left(I-G-A+p_{g m}\right) q p_{g m} / N$ 
Then substituting this expression for $\mathrm{p}_{1}$ into (A2) and solving for $\mathrm{p}$, we get

$$
p=A-\operatorname{Pgm}\left[1+(q / N)\left(1-G-A+p_{g m}\right)\right]
$$

Now substituting from (A5) and (A6) into (A4), we get a single equation in pgm ( $x$ from now on) which we write as

$$
h(x)=f(x)
$$

where

$$
h(x) \equiv x(1-G-A+x)
$$

$$
f(x)=(G-x)[A-x-r(q / N) x(1-G-A+x)]
$$

Let $x_{0}=\max (0, G+A-1)$ and $\operatorname{let} x_{1}=\min (A, G)$. It follows that $x_{0}<x_{1}$. We will show that there is no solution to $(A 7)$ with $x \in\left[0, x_{0}\right]$, and that there is a unique solution with $x$ $\in\left(\mathrm{x}_{0}, \mathrm{x}_{1}\right)$. Finally, we will show that that unique solution implies positive solutions for $\mathrm{p}_{1}$ and $\mathrm{p}$.

If $x \in\left[0, x_{0}\right]$, then $h(x) \leq 0$ and $f(x) \geq(G-x)(A-x)>0$. Hence, there is no solution to (A7) with $x \in\left[0, x_{0}\right]$. As regards existence, we already have $h\left(x_{0}\right)<f\left(x_{0}\right)$. Obviously, $h\left(x_{1}\right)>0$. As for $f\left(x_{1}\right)$, if $G \leq A$, then $f\left(x_{1}\right)=0$; while if $G>A$, then $f\left(x_{1}\right)<0$. Therefore, $h\left(x_{1}\right)>f\left(x_{1}\right)$. Therefore, by continuity of $f$ and $g$, there exists at least one $x \in$ $\left(\mathrm{x}_{0}, \mathrm{x}_{1}\right)$ that satisfies (A7). As regards uniqueness, straightforward calculation of first derivatives of $h$ and $f$ establishes that $h$ is strictly increasing and $f$ is strictly decreasing on $\left(x_{0}, x_{1}\right)$. Let $x^{*}(q, r)$ denote the unique solution to $(A 7)$. Since $h\left(x_{0}\right)=0$, it follows that $\mathrm{h}[\mathrm{x} *(\mathrm{q}, \mathrm{r})]>0$.

The last step is to show that $\mathrm{p}_{\mathrm{gm}}=\mathrm{x}^{*}(\mathrm{q}, \mathrm{r})$ implies positive solutions for $\mathrm{p} 1$ and $\mathrm{p}$. Since, by $(A 5), p_{1}=(q / N) h\left[x^{*}(q, r)\right]$ and $h\left[x^{*}(q, r)\right]>0$, the solution for $p_{1}$ is positive. We next show that $x^{*}(q, r)+(q / N) h\left[x^{*}(q, r)\right]<A$, which, by $(A 2)$, assures a positive solution for $p$. Since for any given $x \in\left(x_{0}, x_{1}\right), f$ is decreasing in $r$, it follows that $x^{*}(q, r)$ and $h\left[x^{*}(q, r)\right]$ are decreasing in $r$. Therefore, if $x^{*}(q, 0)+h\left[x^{*}(q, 0)\right]<A$, then $x^{*}(q, r)+(q / N) h\left[x^{*}(q, r)\right]$ $<A$. It is immediate from $(A 7)$ that $x^{*}(q, 0)=G A$ and $x^{*}(q, 0)+h\left[x^{*}(q, 0)\right]=G A(2-G-$ 
$A+G A)=A\left[2 G-G^{2}-A G(1-G)\right]$. Straighforward calculation shows that $\left[2 G-G^{2}-\right.$ $A G(1-G)]$ is strictly increasing in $G$ for $G \in[0,1]$ and equals 1 at $G=1$. Thereforc, $\mathrm{x}^{*}(\mathrm{q}, 0)+\mathrm{h}\left[\mathrm{x}^{*}(\mathrm{q}, 0)\right]<\mathrm{A}$, as required.

The claims about the dependence of the solutions for $\mathrm{p}_{\mathrm{gm}}$ and $\mathrm{p}_{1}$ on $\mathrm{r}$ follow from the fact that $f$ is decreasing in $r$. Since $f$ is also decreasing in $q$ for $x \in\left(x_{0}, x_{1}\right)$ and $r>0, x^{*}(q, r)$ and $h\left[x^{*}(q, r)\right]$ are also decreasing in $q$ for $r>0$. This and the fact that $x^{*}(q, 0)=G A$ imply the claims about the dependence on $q$.

Proposition 1. A necessary and sufficient condition for existence of a steady state in which matured securities exchange at $\operatorname{par}\left(c_{0}=c_{m}\right)$ and newly issued securities exchange at a discount $\left(0<c_{2}<c_{0}\right)$ is $r>0$. Moreover, if $r=0$, then there is a steady state in which securities always exchange at par $\left(0<c_{2}=c_{0}=c_{m}\right)$.

Proof of necessity. (If there exists a symmetric steady state with $c_{0}=c_{m}>0$ and $c_{2}<c_{m}$, then $r>0$.) We do a proof by contradiction. In particular, we assume $r=0$ and $c_{0}=c_{m}>$ 0 and show that a consequence is $c_{2}=c_{m}$. By (15) and (11), we have only to show that $\mathrm{V}_{1}=\mathrm{V}_{\mathrm{m}}$. With $\mathrm{r}=0$, the right-hand side of (13) becomes $\alpha \max \left[\mathrm{u}\left(\mathrm{c}_{0}\right), \beta \mathrm{V}_{0}\right]+(1-\alpha) \beta \mathrm{V}_{0}$. However, by (11), $c_{0}=c_{m}$ implies $V_{m}=V_{0}$, which, by (12), implies $c_{m 0}=0$. It follows that the right-hand side of $(10)$ is aIso equal to $\alpha\left[u\left(c_{0}\right), \beta V_{0}\right]+(1-\alpha) \beta V_{0} \cdot$

Proof of sufficiency. (If $r>0$, then there exists a (symmetric) steady state with $0<c_{2}<c_{1}$ $=c_{0}=c_{1 n}$. Moreover, if $r=0$, then there is a steady state in which securitics always exchange at par $\left(0<c_{2}=c_{0}=c_{m}\right)$ ) $)$ The conjectured trading pattern is very simple. Since one-period securities are equivalent to matured securities to potential recipients, which, in turn, are by hypothesis equivalent to money, there are no trades involving securities on both sides of the transaction. Moreover, we must have $\delta_{\mathrm{m}}=\delta_{0}=1$. Given this trading pattern, Lemma 4 shows that equations $(5)-(7)$ have a unique positive solution for ( $\mathrm{p}_{1}$, $\left.\mathrm{p}_{0}+\mathrm{pm}_{\mathrm{m}}, \mathrm{Pgm}\right)$, a solution that satisfies $\mathrm{pgm}_{\mathrm{g}}<\mathrm{G}$.

We next show that (9)-(12) have a solution that satisfies the conclusions. If $c_{0}=c_{m}$ and $\mathrm{V}_{0}=\mathrm{V}_{\mathrm{m}}$, then the right-hand side (9) can be written $\alpha \max \left[\mathrm{u}\left(\mathrm{c}_{0}\right), \beta \mathrm{V}_{0}\right]+(1-\alpha) \beta \mathrm{V}_{0}$. But, then, (9)-(12) correspond exactly to (1)-(4). Therefore, lemma 1 implies that there is a unique positive solution with $c_{0}=c_{11}=c^{*}$ and with $V_{0}=V_{m 1}=V^{*}$. It remains only to examine the expression for $\mathrm{V}_{1}$ in (13). 
If $r=0$, then the right-hand side of (13) is $\alpha\left[u\left(c_{0}\right), \beta V_{0}\right]+(1-\alpha) \beta V_{0}$, which implies that there is steady state with securities always at par. If $r>0$, then the right-hand side of (13) can be written $\alpha^{\prime}\left[u\left(c_{0}\right), \beta V_{0}\right]+\left(1-\alpha^{\prime}\right) \beta V_{0}$, where $\alpha^{\prime}<\alpha$. Since, as shown in lemma 1 , $u\left(c^{*}\right)>\beta V^{*}$, it follows that if $r>0$, then $V_{1}<V^{*}$. By (15), this implies that if $r>0$, then $c_{2}<c^{*}$,

Lemma 5. If in a steady state money has value, matured securities trade at a discount, and private agents hold securities, then trade occurs in any single coincidence meeting in which the consumer has a more valuable asset than the producer $\left(\delta_{\mathrm{m}}=\delta_{0}=\delta_{\mathrm{m} 0}=1\right)$. Morcover, if $r=0$, then the unique positive solution to (5)-(8) in such a steady state satisfies: (i) pgm $=\mathrm{G}(1-\mathrm{N} \alpha)$ and (ii) $\mathrm{p}_{1}+\mathrm{p}_{0}=\mathrm{q} \alpha(1-\mathrm{N} \alpha)(1-\mathrm{G})\left[1+\mathrm{G}\left(1-\mathrm{N}^{-1}\right)\right]$.

Proof. We first show that if $V_{m}>0$ and $V_{0} \leq V_{m}$, then $V_{m} \geq V^{*}$ and $V_{0} \geq V^{*}$, where $V^{*}$ is the lemma 1 solution for valued money. By $(10), V_{m} \geq \alpha u\left(c_{m}\right)+\gamma \beta V_{m}+(1-\alpha-\gamma) \beta V_{m}$ $=\alpha u\left(c_{m}\right)+(1-\alpha) \beta V_{m}$, where $\gamma=\left(p_{1}+p_{0}\right) / N$. Therefore, by $(11),[\alpha+(1-\beta) / \beta] c_{m} \geq$ $\alpha u\left(c_{m}\right)$. However, this implies that $c_{m} \geq c^{*}$, which by (11) gives $V_{m} \geq V^{*}$. Since, by hypothesis, $V_{m} \geq V_{0}$, it follows from (9) that $V_{0} \geq \alpha u\left(c_{0}\right)+(1-\alpha) \beta V_{0}$. Then, by (11), we have $[\alpha+(1-\beta) / \beta] c_{0} \geq \alpha u\left(c_{0}\right)$. Since $c_{0}=0$ is not consistent with $V_{m}>0$ (according to (9)), it follows that $c_{0} \geq c^{*}$.which implies $V_{0} \geq V^{*}$.

Next we show that if $\mathrm{V}_{\mathrm{m}}>\mathrm{V}_{0}>0$ and $\mathrm{p}_{1}+\mathrm{p}_{0}>0$, then (a) $\mathrm{u}\left(\mathrm{c}_{\mathrm{m} n \mathrm{O}}\right)+\beta \mathrm{V}_{0}>\beta \mathrm{V}_{\mathrm{m}}$, (b) $u\left(c_{0}\right)>\beta V_{0}$, and $(c) u\left(c_{m}\right)>\beta V_{m}$. Suppose that (a) does not hold. Then, by $(10), V_{m}=$ $V^{*}$. It follows from $V_{0} \geq V^{*}$ that $V_{0} \geq V_{m b}$ a contradiction. Conclusions (b) and (c) are established by showing that if either does not hold, then the steady state asset distribution does not have securities outstanding. Suppose, first, that (b) does not hold. Then, by (11), $c_{0} \geq u\left(c_{0}\right)$. Since $c_{m}>c_{0}$, it follows that $\beta V_{m}=c_{m}>u\left(c_{m}\right)$. Thus, we have the conclusion that neither matured securities nor money are traded in single-coincidence mectings when the producer has no asset. However, that implies that government agents never acquire assets; that is, the right-hand side of (7) is zero. It also implies, by (6), that the left-hand side of (7) is equal to $\mathrm{p}_{1}$, which, therefore, is zero. Then, by (8), so is the stock of matured securitics in private hands. It follows that if (b) does not hold, then there is no steady state with securitics in private hands. Suppose now that (c) does not hold. Then $\delta_{\mathrm{m}}=0$. It follows that the Ieft-hand side of (7) is $\mathrm{p}_{1}$, while the right-hand side is a fraction of $\mathrm{p}_{1}$. Again, there is no steady state with either $\mathrm{p}_{1}$ or poor both positive.

Conclusions (i) and (ii) of the lemma follow from results in the proof of lemma 4 and (8). 
Proposition 2. Assume $\mathrm{r}=0$ (government agents treat one-period securities as do private agents). If $\mathrm{G}$ is sufficiently close to 0 and $(1-\beta) / \beta \geq q \alpha(1-\mathrm{N \alpha}) / \mathrm{N}$, then there cxists a steady state with matured securities exchanging at less than par $\left(c_{0}<c_{m}\right.$ and $\left.c_{m 0}>0\right)$ and with newly issued securities valued at less than matured securities $\left(c_{2}<c_{0}\right)$.

Proof. We conjecture that there is a solution satisfying the conclusions and verify that there is. The proof uses the recursive structure of the conditions in definition 2 that we noted above. We have already described, in lemma 5 , the solution for the asset distribution under the conjectured trading pattern. The next step is to show that equations (9)-(12) have a solution with $c_{m}>c_{0}>0$, a solution that is consistent with the conjectured trading pattern. To do that we rely on the implicit function theorem, lemma 3 , and the correspondance between (9)-(12) and (1)-(4) with $\left(\mathrm{c}_{0}, \mathrm{c}_{\mathrm{m}}, \mathrm{c}_{\mathrm{m} 0}, \mathrm{~V}_{0}, \mathrm{~V}_{\mathrm{m}}\right)$ corresponding to $\left(\mathrm{c}_{\mathrm{A}}, \mathrm{c}_{\mathrm{B}}, \mathrm{c}_{\mathrm{BA}}, \mathrm{V}_{\mathrm{A}}\right.$, $\mathrm{VB})$.

We first show that the right-hand sides of (9) and (10) are continuous in $G$ and approach the right-hand sides of (1) and (2), respectively, as $G \rightarrow 0$. Since $p_{g m}=G(1-N \alpha)$, the right-hand side of $(9)$ is continuous in $G$ and approaches $\alpha u\left(c_{0}\right)+(1-\alpha) \beta V_{0}$, which is the same as the right-hand side of (1). G appears in (10) implicitly by way of the sum $p_{1}+p_{0}$, which is continuous in $G$ and approaches $q \alpha$ ( $(1-N \alpha$ ) as $G \rightarrow 0$ (see (ii) of lemma 5). Thus, the right-hand side of $(10)$ is continuous in $G$ and approaches the right-hand side of (2) as $G \rightarrow 0$, provided we replace $p_{A}$ in (2) by $q \alpha(1-N \alpha)$.

To apply the implicit function theorem to (9)-(12), we need two other conditions. First, the solution at $\mathrm{G}=0$ must be in the interior of the domain. Since the solution in lemma 3 satisfies $0<\mathrm{c}^{*}=\mathrm{c}_{\mathrm{A}}<\mathrm{CB}_{B}$, that condition is met. We also need to satisfy the nonvanishing Jacobian condition at $G=0$. That condition is implied by two features of the solution in lemma 3: first, the solution for $\mathrm{c}_{\mathrm{A}}$ in lemma 3 , which is $\mathrm{c}^{*}$, satisfics $[\alpha+(1-\beta) / \beta]>$ $\alpha u^{\prime}\left(c^{*}\right)$; second, the positive solution to $F(x)=H(x)$ in lemma 3, denoted $x^{*}$, satisfies $F^{\prime}\left(x^{*}\right)>H^{\prime}\left(x^{*}\right)$.

It follows, then, from the implicit function theorem applied to (9)-(12) under the conjectured trading pattern that for $G$ sufficiently close to zero those equations have a solution in the neighborhood of the lemma 3 solution. We denote that solution $\left(c_{\mathrm{m}}{ }^{*}(G), c_{0}^{*}(G), c_{n n} 0^{*}(G), V_{0} *(G), V_{1 n}{ }^{*}(G)\right)$. Since, as established in lemma 3 , the lemma 3 solution satisfies the optimization conditions with strict inequalities, it follows from 
continuity of the solution to (9)-(12) in G that those strict inequalities also hold for the solution to (9)-(12) for $\mathrm{G}$ sufficiently close to zero.

The rest of the proof proceeds recursively to find $V_{1}$ and $c_{2}$. Existence is immediate. The properties of the solution follow from studying $\mathrm{V}_{0}-\mathrm{V}_{1}$. By $(9)$ and (13), $\mathrm{V}_{0}-\mathrm{V}_{1}=[(\mathrm{G}-$ $\left.\left.\mathrm{p}_{\mathrm{gm}}\right) / \mathrm{N}\right]\left[\mathrm{u}\left(\mathrm{c}_{\mathrm{m}}\right)-\mathrm{u}\left(\mathrm{c}_{0}\right)\right]+\left[\mathrm{G}-\left(\mathrm{G}-\mathrm{Pgm}_{\mathrm{gm}}\right) / \mathrm{N}\right] \beta\left(\mathrm{V}_{\mathrm{m}}-\mathrm{V}_{0}\right)$. Since this is positive when evaluated at the above solution to (9)-(12), it follows that the solution for $V_{1}$, denoted $V_{1} *(G)$, satisfies $V_{1} *(G)<V_{0}^{*}(G)$. It follows that the solution for $c_{2}$, denoted $c_{2}^{*}(G)$, satisfies $c_{2} *(G)<c_{0}^{*}(G)$. 